\title{
Reproductive, Maternal, Newborn, Child and Adolescent Health and related Behaviour Change Communication strategies in Bangladesh, Nepal and India: A narrative review
}

\author{
Shradha S. Parsekar ${ }^{\mathrm{a}}$, Prachi Pundir ${ }^{\mathrm{b}, *}$, Valeria Bevilacqua ${ }^{\mathrm{b}, 1}$ \\ ${ }^{a}$ Department of Community Medicine, Kasturba Medical College, Manipal, India \\ ${ }^{\mathrm{b}}$ Public Health Evidence South Asia, Prasanna School of Public Health, Manipal Academy of Higher Education, Manipal, India
}

\section{A R T I C L E I N F O}

\section{Keywords:}

Reproductive, Maternal, Newborn, Child and

Adolescent Health

Behaviour Change Communication

India, Bangladesh and Nepal

\begin{abstract}
A B S T R A C T
Aim: The review was conducted to collate the evidence on the current status of "Reproductive, Maternal, Newborn, Child and Adolescent Health" (RMNCAH) and related Behaviour Change Communication (BCC) interventions in RMNCAH in South Asia, particularly Bangladesh, Nepal and India.

Methods: Literature search was conducted on multiple databases and websites in March 2019. The search was limited to English language publications. The data on health indicators for the eight South Asian countries are compared in the review. This review narratively summarises the key RMNCAH and related BCC initiatives undertaken in Bangladesh, Nepal and India.

Results: The South Asian countries have achieved significant progress in socio-economic indicators related to health aligned with the Millennium Development Goals but face a number of challenges. There has been a significant development in financial incentives, programmes and policies framed for improving indicators of maternal and child health. Various RMNCAH initiatives which impact positively on maternal and child health indicators were identified.

Conclusion: Bangladesh, Nepal and India have made substantial improvement in maternal and child health indicators but at a slower pace than other countries of South Asia, in relation to which consistent disparities still exist. There are a number of BCC initiatives targeting RMNCAH. The improvement in RMNCAH indicators can be attributed to multiple initiatives wherein the contribution of BCC is relevant, because of their wide community outreach and effectiveness among all age-groups.
\end{abstract}

\section{Introduction}

"Maternal and child health" ( $\mathrm{MCH}$ ) has increasingly been recognised as an economic priority, both globally and within countries themselves. ${ }^{1,2}$ The health of individuals, families and communities in developing countries of South Asia (SA), has increasingly been supported by different actors through a combination of approaches. "Reproductive, Maternal, Newborn, Child and Adolescent's Health" (RMNCAH) is one such approach under the "continuum of care" concept, being characterized by a more holistic scope. The design, implementation, monitoring and evaluation phases of health interventions modify accordingly, in the endeavor to integrate evidence-based, bottom-up, participatory approaches in the project cycle, such as Behaviour Change Communication (BCC). ${ }^{4}$
BCC interventions "are a set of activities within a project or programme which are strategically designed and implemented to contribute to the process of changing behaviours, as a means of contributing to improved health outcomes". 5 Effective BCCs strategies require experts' knowledge, availability of funds along with creativity, innovation and a contextsensitive approach to the factors that encourage certain behaviours related to good health. Identifying the appropriate population, a particular modification in the behaviour and the ways in which BCC is delivered to reach the population are also important factors to be considered for developing an approach. ${ }^{5}$ The messages should be designed using culturally contextualised content to support individuals and communities in modifying high risk practices and delivered through a combination of mediums and at different levels. ${ }^{6}$

Millennium Development Goals (MDGs) were introduced by the

\footnotetext{
${ }^{*}$ Corresponding author. Room No. 27, Public Health Evidence South Asia, Prasanna School of Public Health, Manipal Academy of Higher Education, Neat Tiger Circle, Madhav Nagar, Manipal, Karnataka, 576104, India.

E-mail address: prachipundir2012@gmail.com (P. Pundir).

${ }^{1}$ Department of Anthropology and Sociology, School of Oriental and African Studies, University of London.
} 
United Nations (UN) in 1990 and had specific goals and targets for all countries to be achieved by 2015 . Reduction of child mortality and improving maternal health were goal 4 and 5 of MDGs, respectively. ${ }^{7}$ At completion of the time-period for achieving MDG, Sustainable Development Goals (SDGs) were introduced by UN in 2015, which are to be achieved by 2030. Goal 3 of SDGs "Ensure healthy lives and promote wellbeing for all ages" covers the MCH component. ${ }^{8}$ Country-wise progress towards the goals is tracked by surveys such as Multiple Indicator Cluster Surveys, developed by UNICEF, ${ }^{9}$ which provides a base for decisions and actions by the governments. In this early phase of the SDGs, it is important to look back at the achievements and shortfalls to reflect on lessons learned on RMNCAH strategies in order to reach SDG targets in the SA context.

According to a 2018 "World Health Organization" (WHO) report, $99 \%$ of the maternal deaths occur in low-and-middle-income-countries (LMICs). ${ }^{10}$ Considering this fact, organizations such as "United States Agency for International Development" (USAID) has prioritised the countries where there is high child and maternal deaths so as to cut down these preventable deaths. ${ }^{11}$ Bangladesh, India and Nepal are LMICs in SA with weak MCH indicators, in addition to sharing borders and demographic characteristics. These three countries are experiencing demographic and epidemiological transition with dual burden of communicable and noncommunicable diseases. ${ }^{12}$ However, there is diversity with regards to disease burden on inter-and-intra-country comparison. ${ }^{12}$ In addition to high population density, these three countries have high poverty rates ${ }^{13}$ and due to various reasons inequality with regards to income-expenditure and opportunity is found to be increasing. ${ }^{14}$ Subsequently, inequality affects education, health and other development of people especially belonging to impoverished group. Additionally, in the recent past, these three countries have faced natural calamities such as floods and earthquakes, and are currently under refugee crisis and terrorism threat, all of which affects MCH. In order to extemporize the socio-economic development of the country, improvement in $\mathrm{MCH}$ is one of the fundamental strategy.

Prior literature have summarised the key $\mathrm{MCH}$ indicators of individual countries of SA however, reviews did not include evidence of BCC components within RMNCAH. ${ }^{13}{ }^{15}-17$ There is an acute need to acknowledge the growing application of BCC strategies in the RMNCAH arena and to find ways to improve the health status of vulnerable population. Evidence from the area-and-context-specific effective programs and interventions is pivotal in order to produce a permanent positive healthy behavioural (and social) change. Therefore, this review was conducted to collate the evidence on existing status of RMNCAH and BCC interventions in RMNCAH in countries of SA, particularly Bangladesh, Nepal and India.

\section{Methodology}

We conducted a narrative review by searching key sources in the RMNCAH subject area. WHO, UN, USAID, "United Nations Children's Fund" (UNICEF), "United Nations Population Funds" (UNPF), "World Bank", India and Bangladesh's "Ministry of Health and Family Welfare" (MOHFW), and Nepal's "Ministry of Health and Population" were the organization and country websites searched for relevant reports. Peerreviewed English articles were also searched on JSTOR, EBSCO, Google Scholar, PubMed and MedIND in March 2019. Although, the review has included published reports from the year 2000 onwards, it includes reference to policies or programmes that had come into force prior to 2000 when they appear of particular relevance.

We included MCH related indicators to compare the status in SA countries especially Bangladesh, India and Nepal, identified through reports published by major organizations such as World Bank, WHO, UNICEF and subsequent government reports. We also included other publications which reported country level data and excluded pilot studies or interventions which were not scaled up to regional or national level. We focused on major RMNCAH and BCC related initiatives launched in Bangladesh, India and Nepal. In case we identified differences in health indicators reported by various organization we considered World Bank, WHO, UNICEF and other international organizations in order stated above to rule out any discrepancy. The review considered following countries as comprising of SA: "India, Bangladesh, Nepal, Sri Lanka, Bhutan, Pakistan, Afghanistan, and Maldives". ${ }^{18}$ The data on health indicators for the eight countries of SA have been compared in the review and presented in tables and narratively summarises the key RMNCAH and related BCC initiatives undertaken in three countries.

Initial search was carried out by one author (VB) in 2016 which was updated by another author (PP) in December 2017, furthermore, it was updated by one author (SP) in March 2019. Probable list of documents and articles were shortlisted by one author (SP) which was read by two authors (SP and PP) independently. Discussion was held between the authors till consensus and recent available findings were extracted and updated in the document by two authors (SP and PP).

\section{Results}

\subsection{The current status of RMNCAH in SA and associated policies, programmes and strategies}

The poor status of $\mathrm{MCH}$ in SA which can mainly be attributed to status of women, inequity, poverty and illiteracy. ${ }^{19}$ Although countries in SA have shown significant achievement in indicators aligned with the MDGs such as drop in poverty and improved education and healthcare facilities, but the progress varies across the countries. The status of $\mathrm{MCH}$ care is dramatically better in Maldives and Sri Lanka than in the other countries. ${ }^{20}$ Except Pakistan and Afghanistan, SA is Polio free; the most recent SA country to declare polio free in 2014 was India, which is an important achievement. Elimination of maternal and neonatal tetanus was another milestone achieved by India in $2015 .{ }^{21}$ The latest available country level health indicators of SA are provided in Table 1.

In the phase of transition from MDGs to SDGs, the SA region still faces a number of challenges, such as lack of basic data collection to monitor MCH progress (around 33\% of infants younger than 12 months having registered births). ${ }^{23}$ Neonatal and child deaths attributable to vitamin A deficiency and underweight is still present and need to be further addressed. ${ }^{23}$ The percentage of neonates with low birth weight in SA (estimated 28\%) remains high as compared to East Asian and Pacific countries (6\%). ${ }^{23}$ However, in respect to sexual and reproductive health, there is a reduction in primary infertility (non-voluntary childlessness) since $1990 .^{23}$ The contraceptive prevalence rate of women in reproductive age was found to be the highest in Sri Lanka (68.4\%). Among the 15-49 year-old, the HIV/AIDS prevalence rate was the highest in Nepal. ${ }^{23}$ In respect to education in SA overall, indicators such as the "Human Development Index", "Human Poverty Index", "Gender Development Index", and "Gender Empowerment Index" demonstrate a weak ranking, except Sri Lanka and Maldives. ${ }^{23}$

\subsection{Progress in attaining Millennium Development Goals 4 and 5}

In the first decade of the millennium, countries in the SA made substantial efforts to accelerate progress towards MDGs, specially MDG 4 and $5 .^{7}$ While the other countries were striving to reach the targets, in 2013, Bangladesh and Nepal were ranked within the ten "fast-track countries" that showed advancement in achieving MDG 4 and 5 globally. ${ }^{24}$ In SA region, a considerable advancement in MDG 4 was recorded, but the progress differed within and between countries. Reduction in deaths were attributed to improved coverage of welldesigned strategies achieved by a range of community-focused and national campaign or programmatic approaches along with improvements in socioeconomic conditions. ${ }^{25-27}$ Countdown to 2015 for MDG and 2030 for SDG provides independent and rigorous analyses and costeffective interventions to improve $\mathrm{MCH} .{ }^{28}$ 
Table 1

Health indicators of South Asian countries.

\begin{tabular}{|c|c|c|c|c|c|c|c|c|}
\hline Indicators & Maldives & Sri Lanka & Bhutan & Bangladesh & Nepal & India & Pakistan & Afghanistan \\
\hline IMR/1000 live births* (2017) & 6.8 & 7.5 & 25.6 & 26.9 & 27.8 & 32 & 61.2 & 51.7 \\
\hline U5MR/1000 live births* (2017) & 7.9 & 8.8 & 30.8 & 32.4 & 33.7 & 39.4 & 74.9 & 67.9 \\
\hline MMR/100,000 live births* (2015무) & 68 & 30 & 148 & 176 & 258 & 174 & 178 & 396 \\
\hline $\begin{array}{l}\text { Children } 12-23 \text { months receiving measles immunization } \\
(\%) *(2017)\end{array}$ & 99 & 99 & 97 & 94 & 90 & 88 & 76 & 62 \\
\hline DPT3 immunization 12-23 months (\%)*(2017) & 99 & 99 & 98 & 97 & 90 & 88 & 75 & 65 \\
\hline Pregnant women receiving at least 4 ANC visits (\%) للا & 85 (2009) & 93 (2007) & 85 (2015) & $31(2014)$ & 69 (2016) & $51(2015)$ & 37 (2013) & $18(2015)$ \\
\hline Skilled birth attendants (\%) ${ }^{\boldsymbol{\Lambda}} *$ & $95.6(2014)$ & $\begin{array}{l}98.6 \\
(2007)\end{array}$ & 89 (2016) & $49.8(2016)$ & $58(2016)$ & $\begin{array}{l}85.7 \\
(2016)\end{array}$ & $52.1(2013)$ & 50.5 (2015) \\
\hline $\begin{array}{l}\text { Contraceptive prevalence rate (any method), women 15-49 } \\
\text { years }(\%)^{*}\end{array}$ & 34.7 (2009) & $\begin{array}{l}61.7 \\
(2016)\end{array}$ & $65.6(2010)$ & $62.4(2014)$ & $\begin{array}{l}52.6 \\
(2016)\end{array}$ & $\begin{array}{l}53.5 \\
(2016)\end{array}$ & $35.4(2013)$ & 22.5 (2015) \\
\hline Doctors (physicians)/1000 Population* & $3.61(2015)$ & $\begin{array}{l}0.88 \\
(2015)\end{array}$ & $0.4(2016)$ & $0.47(2015)$ & $0.6(2014)$ & $\begin{array}{l}0.76 \\
(2016)\end{array}$ & $0.98(2015)$ & $0.30(2016)$ \\
\hline Hospital Beds/1000 Population* & $4.3(2009)$ & $3.6(2012)$ & $1.7(2012)$ & $0.8(2015)$ & $0.3(2012)$ & $0.7(2011)$ & $0.6(2014)$ & $0.5(2015)$ \\
\hline Total Health Expenditure as \% GDP (2015) * & 11.495 & 2.966 & 3.486 & 2.639 & 6.147 & 3.888 & 2.689 & 10.298 \\
\hline
\end{tabular}

Data source: The World Bank*; UNICEF ${ }^{\Downarrow}$; UNICEF-WHO ${ }^{\wedge}$

(ANC: Ante-natal care, IMR: Infant mortality rate, U5MR: Under five mortality rate, MMR: Maternal mortality ratio, DPT: Diphtheria Pertussis Tetanus, GDP: Gross Domestic Products).

Latest data for MMR is from 2015, because MMR is calculated every five years. ${ }^{22}$

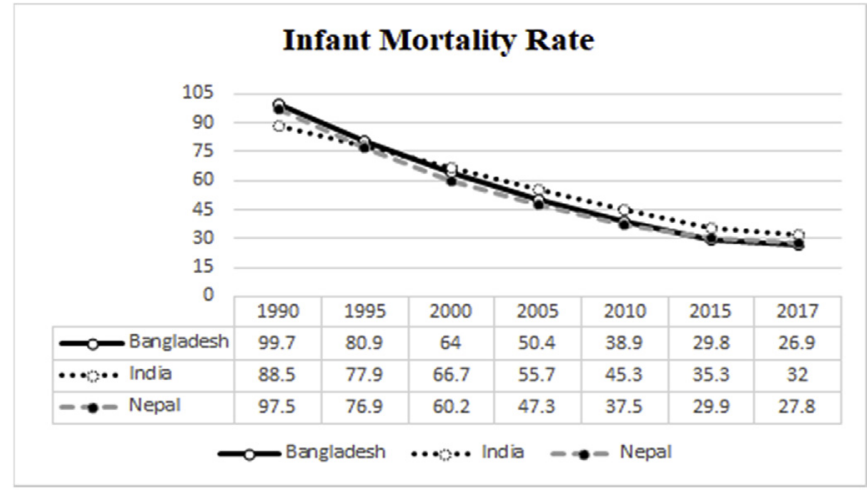

Note: Authors' creation of figure based on World Bank, 2019 data

Fig. 1. Comparison of infant deaths (per 1000 live births) in Bangladesh, Nepal and India.

Note: Authors' creation of figure based on World Bank, 2019 data.

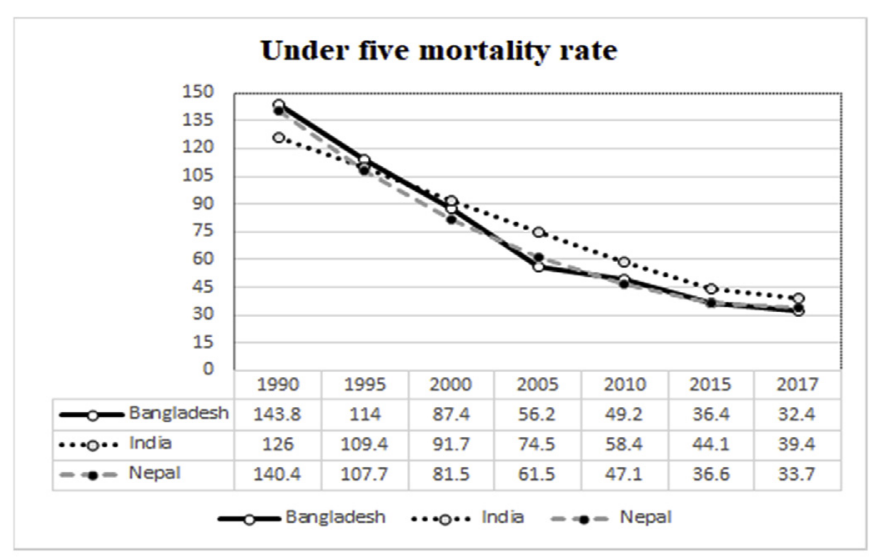

Note: Authors' creation of figure based on World Bank, 2019 data

Fig. 2. Comparison of child [under-five] deaths (per 1000 live births) in Bangladesh, Nepal and India.

Note: Authors' creation of figure based on World Bank, 2019 data.

"Infant Mortality Rate (IMR) per 1000 live births" has declined in Bangladesh, Nepal and India from 1990 to 2017 (depicted in Fig. 1). While Bangladesh and Nepal had a higher IMR than India in 1990, in
2015, the two countries came closer to the target of IMR 27 as per MDG 4 , surpassing India, suggesting a better performance. ${ }^{29}$ As portrayed in Fig. 2, a trend similar to IMR was seen in under-five mortality rate (U5MR) for the three countries. While Bangladesh and Nepal surpassed the MDG 4 target of 42 to reach U5MR of 36 by 2015, India could only reach U5MR of $45 .{ }^{30}$ However, the projected deaths among children in India have been reduced from 3.36 million (1990) to 1.2 million (2015). ${ }^{25}$ In 2017, U5MR further declined in all three countries, which needs to be further reduced as per SDG target of 25 per 1000 live births by 2030 .

India's National health policy (NHP) 2017 has laid down the target of Neonatal Mortality Rate (NMR) of 16/1000 live births by 2025 and SDG target of 12 by 2030, similarly for IMR, NHP set a target of 28/ 1000 by $2019 .{ }^{31}$ NHP of India has set a target for U5MR of $23 / 1000$ by 2025 whereas Bangladesh has set it as 37 by 2021 but SDG wants it to be under 25 by $2030 .{ }^{13}$ In 2016, U5MR in India was 39, IMR was 34 and NMR was 24 per 1000 live births accounting to an estimated 960,000 under-5 child deaths annually, of which NMR constitutes $61 \%$ $(630,000)$ of under-5 deaths. Every year, only four Indian states (Rajasthan, Bihar, Madhya Pradesh, and Uttar Pradesh) contribute to the highest NMR (56\%) of the total NMR in India and 14\% NMR globally. ${ }^{31,32}$ Similar to India, NMR in Nepal also constitutes $61 \%$ of child deaths in 2011 and it constitutes $72 \%$ of IMR. ${ }^{26}$ In India, NMR is higher among females as compared to males and it is two times higher in rural areas as compared to urban areas. ${ }^{32}$ The above figures suggests there is within country disparity in India, similar disparity also exist in Nepal and Bangladesh. Additionally, one of the major concern for Nepal with regards to NMR was that it remained stationary (33/1000 live births) between 2006 to $2011 .^{26}$

Maternal deaths have reduced over the last three decades in SA. The reduction in Maternal Mortality Ratio (MMR, calculated as per thousand live births) is attributable to various reasons, such as better accessibility and utilisation of healthcare services (including road transport system improvement), advancement in women empowerment and per capita income as well as fall in total fertility rate (TFR). ${ }^{25-27} \mathrm{~A}$ collaborative report estimated a decline of $65 \%$ in MMR in SA region from 1990 to $2013 .{ }^{15}$ With respect to individual nations, Nepal has shown a drastic decline in MMR compared to slow pace in other two countries (depicted in Fig. 3) however, all three countries could not reach close to the MDG 5 target of MMR $109 .{ }^{15}$ To improve it further, India and Bangladesh have set targets of MMR 100 by $2020^{31}$ and 105 by 2021 in their respective NHP (2017). ${ }^{13}$ In Nepal TFR dropped from 5.3 to 2.6 between 2006 and 2011 from five births per woman in 1990 to two in 2014 in Bangladesh. In Nepal, it was partly due to migration 


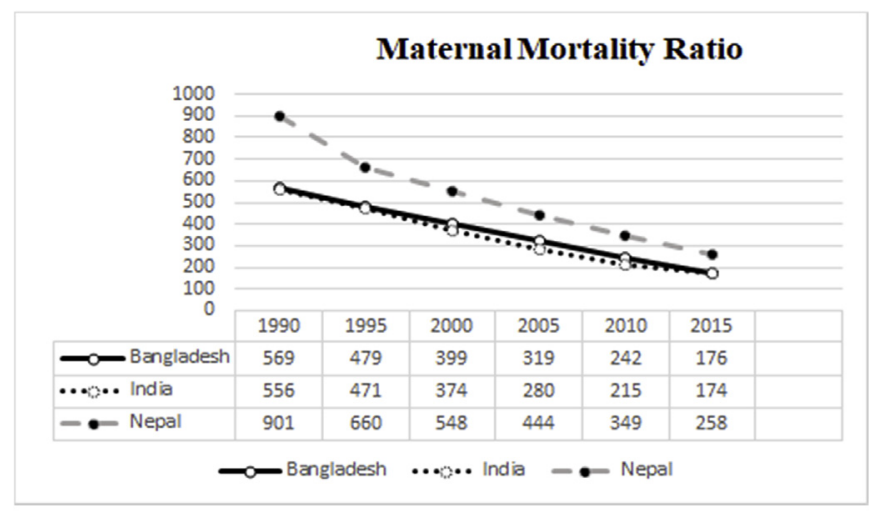

Note: Authors' creation of figure based on World Bank, 2019 data

Fig. 3. Comparison of maternal deaths (per 100000 live births) in Bangladesh, Nepal and India.

Note: Authors' creation of figure based on World Bank, 2019 data.

of a spouse for purpose of employment leading to spousal separation. $^{26,27}$ However, the TFR in Nepal differs with economic status, education, and place of residence. ${ }^{33}$

Although remaining low, the share of pregnant women who received at least one antenatal care (ANC) check-up from a trained healthcare provider rose from approximately one in four in the early 1990s to approximately three out of five in 2014, in Bangladesh. There is a rise in rates of institutional births as well as births undertaken by a "skilled birth attendant" (SBA) in Nepal. ${ }^{26,27}$ Nevertheless, three countries need to strengthen its strategies to reduce the MMR to 70 by 2030 as set by SDG. ${ }^{8}$

\subsection{Status of RMNCAH and BCC in Bangladesh, India and Nepal}

Political commitment to improve MCH thorough adhering to the healthcare policies has been the prime obligation of consecutive governments in India, Bangladesh and Nepal. Moreover, governments, development partners, donors, professionals and the NGO sector have mutually collaborated in the delivery of healthcare services. This resulted in facilitated widespread coverage of many health interventions, in turn leading to advancement towards attaining MDGs 4 and $5 .{ }^{26,27,34}$ There has been a development in financial incentives, programmes and policies framed for the improvement of $\mathrm{MCH}$ indicators. A well-implemented BCC approach to RMNCAH should have the capability to trigger or maintain healthy practices which, in turn, will improve reproductive health and adolescent, maternal and newborn health. ${ }^{34}$ Some of the strategies and programme summaries are listed in Table 2, and few of the initiatives which included successful BCC interventions for RMNCAH in Bangladesh, India and Nepal are described below.

Every Newborn Action Plan (ENAP) (2014-2030): ENAP is the global action plan endorsed by WHO and UNICEF which aims to "end preventable newborn mortality and stillbirths and contribute to reducing maternal mortality and morbidity". In 2017, Bangladesh, India and Nepal were among the 48 countries which integrated the ENAP into their national health strategies. The report stated "notable strides in the past 15 years" in area of "exclusive breastfeeding" among SA countries. ${ }^{42}$ The levels of healthcare stated under ENAP are: (1) "Community": Home birth with skilled care and clean practices and postnatal home visits for mothers and newborns (2) "First and second level facility": Basic emergency obstetric and essential newborn care (3) "Referral and tertiary level facility": Comprehensive emergency obstetric and essential newborn care. ${ }^{1}$

BCC for Children's Health: The "Meena Communication Initiative" (MCI) was launched by UNICEF, September 1998, as an innovative entertainment-educational tool. Its aim was to promote knowledge about health and wellbeing and build awareness about social issues and children's rights through BCC. MCI has partners in governmental, NGO, private and the media sector. The MCI includes the popular cartoon character of a nine-year old school girl named Meena who challenges social norms, and resulted in significant impact on children's and adolescent's behaviour. The Meena Communication Package (produced in association with $\mathrm{BBC}$ ) consisted of animated films, posters, comic books, teachers' guides and a series of radio programmes. UNICEF's "Regional Office for SA" (ROSA) produced 33 stories by the year 2005 and are available in multiple languages. ${ }^{6}$ The extent of program effectiveness varies across countries, with differing levels of awareness, skills and practices. The MCI, due to the attractiveness and great appeal of the communication materials, media and channels for communication for children's rights, promoted change in life skills practices in audiences from SA region. ${ }^{45}$

\subsection{Bangladesh}

"Reproductive Health Vouchers Programme" (2004) or DSF programme was launched by the MOHFW with WHO support. The scheme provides "three ANC check-ups; safe delivery care in a health facility or at home with SBA; emergency care for obstetrics complications, including caesarean sections; and one postnatal care check-up within six weeks of delivery". It also provides "cash incentives to cover routine and emergency transport, some food and medicine costs for the family; and a small gift box". ${ }^{10}$ In order to improve quality, greater efforts are needed to involve private sector and NGOs, ${ }^{18}$ although there has been an increasing number of beneficiaries under the programme. Compared to the DSF facilities, the government facilities are still in need of quality improvements. ${ }^{35}$

"Transfer Modality Research Initiative" (TMRI): TMRI conducted two randomized controlled trials (2012-2014), one in the northwest region rural areas (North) and second in coastal southern region (South). "UN World Food Programme" and "Eco-Social Development Organization" were the organizations responsible for managing and implementation of nutrition BCC training. There was successful implementation of nutrition in BCC component. This resulted in household (which received BCC training) attendance of about 48 and 49 sittings/annum in North and South, respectively. ${ }^{46}$

\subsection{India}

The RMNCH + A strategy issued by the MOHFW, reviews the status of RMNCAH and related policies and current programmes in India. The strategy aims to improve the $\mathrm{MCH}$ at the country, state, district and subdistrict levels. The RMNCH + A strategy fills the gaps at various life stages leading to subsequent reduction in mortality as well as improved MCH across the country in partnership with National Health Mission (NHM). The NHM improved the accessibility and availability to good quality healthcare for the society at large and especially for the vulnerable population. ${ }^{17}$ The inclusion of adolescence as a distinct "life stage' in the overall strategy signifies the "Plus" in the strategic approach. ${ }^{34}$

$\mathrm{MCH}$ has been linked to reproductive health which further encompasses gender, adolescent health, family planning, HIV, and "PreConception and Pre-Natal Diagnostic Techniques". The aim was to link care at community and facility levels and referrals between various levels of health care system. Creation of a continuous care pathway to have an additive effect on overall outcomes and impact. ${ }^{34}$ Launched in 2014, the India Newborn Action Plan (INAP) is aligned with the Global ENAP $^{28,42}$ and is implemented within the RMNCH + A framework. The core intervention packages under INAP covers care during pre-conception, pregnancy, labour and childbirth; and care for healthy and sick newborns. $^{32}$

"BCC Strategy design to Improve Family Health Outcomes in Rural Uttar Pradesh": Due to the findings on limited reach of BCC, between 
Table 2

List of programmes in Bangladesh, Nepal and India.

\begin{tabular}{|c|c|c|}
\hline Bangladesh & India & Nepal \\
\hline RMNCAH programmes & Programs funded by Government: & Programs funded by Government: \\
\hline $\begin{array}{l}\text { - Health Nutrition and Population Sector Programme and } \\
\text { - Hational Nutrition Programme (2003-2011) } \\
\text { - Health Population and Nutrition Sector Development } \\
\text { Programme }(2011-16)^{27} \\
\text { - Health Population Sector Nutrition programme (2017) } \\
\text { - Reproductive Health Vouchers Programme }(2004) \text { : } \\
\text { funding by government with support by WHO e.g. } \\
\text { - Hemand Side Financing (DSF) } \\
\text { - Health Financing Strategy }(2012-2032)^{27} \text { towards } \\
\text { universal health coverage }\end{array}$ & $\begin{array}{l}\text { - National Health Mission (NHM): "Janani Suraksha } \\
\text { Yojna" (2005) to increase institutional delivery by } \\
\text { providing cash assistance } \\
\text { - "Pradhan Mantri Surakshit Matritva Abhiyan": (2016) } \\
\text { to improvise the ANC }{ }^{31} \\
\text { - "Navjat Shishu Surakha Karyakram" (2009) targeting } \\
\text { newborns } \\
\text { - "Rashtriya Kishor Swasthya Karyakram" (2014) } \\
\text { targeted at adolescent health } \\
\text { - Mother and child tracking system (2009) }{ }^{36} \\
\text { - "Mission Indradhanush" (2014) to control seven } \\
\text { vaccine preventable diseases among infants } \\
\text { - "Save Girls, Educate Girls" (Beti Bachao, Beti } \\
\text { Padhao), "Skill India", "Digital India", "Clean India" } \\
\text { (Swacch Bharat Abhiyan) } \\
\text { Programs supported by Government and external } \\
\text { funding: } \\
\text { - RMNCH + A Strategy }{ }^{34} \text { (2013) to improve overall } \\
\text { RMNCAH }\end{array}$ & $\begin{array}{l}\text { - The Aama Suraksha Karyakram }(2005)^{37} \\
\text { - National Safe Motherhood and Newborn Health } \\
\text { (2006) } \\
\text { - Community Based Newborn care package } \\
\text { - National Policy for SBA }(2006)^{38} \\
\text { - Suaahara project: sector-wide approach to fund } \\
\text { healthcare targeting malnourishment and others }{ }^{26} \\
\text { - National plan of Action for children (2012) } \\
\text { - Multisector plan for accelerating the reduction of } \\
\text { maternal and child under-nutrition in Nepal } \\
(2013-17)^{39}\end{array}$ \\
\hline
\end{tabular}

BCC in RMNCAH Programme

- Healthy Fertility study (2007-2010) funded by USAID ${ }^{40}$

- Transfer Modality Research Initiative (2012-14):

Funded by International Food Policy Research Institute
- BCC Strategy design to improve Family Health Outcomes $^{3}$ (2009-11): funded by Population Council

- Kilkari: a maternal and child health service in India (2016): funded by UKAID ${ }^{41}$

- The Meena Communication Initiative (1998-2005) (India, Nepal, Bangladesh, Bhutan, Sri Lanka and Pakistan): Intervention funded by UNICEF ${ }^{45}$
- Every Newborn Action Plan (2014-2030): WHO and UNICEF strategy integrated into National Health Policies of Bangladesh (National Newborn plan), ${ }^{42}$ India (India Newborn Action plan) ${ }^{32}$ and Nepal (Nepal's Every newborn Action plan) ${ }^{43}$

- 'Improving Sexual and Reproductive Health of Young People by increasing the Age at Marriage and Delaying the First Pregnancy' (2009-2013): Intervention funded by European Union $^{44}$

- Maternal and Child Survival Programme (MCSP) Social and BCC (2008): Funded by USAID ${ }^{11}$

2009 and 2011, the Population Council conducted an analysis to come up with a comprehensive BCC strategy in rural Uttar Pradesh. ${ }^{3}$ The study aimed to understand behaviours that, when not followed, are responsible for $\mathrm{MCH}$ indicators. Based on barriers and enabling factors for each behaviour, effectiveness of various communication modes and role of different ways of communication were studied and collaborated with broadcasting agencies. An integrated BCC strategy and list of measurable outcome indicators were identified to improve family health outcomes was developed based on the aforementioned findings. The strategy was published in a book ${ }^{47}$ and is widely followed throughout India. The Population Council also conducted similar study in Bihar. The study has resulted in gaining attention of the donors towards BCC in India. ${ }^{3}$

\subsection{Nepal}

The "Aama Surakshya Karkam" (2005) - (Aama or mother) was launched as "Maternity Incentive Scheme" which was later renamed as the "Safe Delivery Incentives Programme" (SDIP). In January 2009, all types of childbirths in government healthcare institutions across the nation were made available for free and the scheme was extended to include some accredited private facilities. ${ }^{37}$ Women receive free delivery care, transport costs and monetary benefits (approximately USD four). Women belonging to low socio-economic strata, residing in hard to reach areas such as hilly (USD 10) and mountain (USD 15) and in Terai (USD five) district were eligible to receive higher amount. ${ }^{26}$ An incentive to the health staff is also given for attending institutional and home delivery. ${ }^{26}$ The evaluation of Aama programme in 2010 raised the issue of uneven awareness of and access to free delivery care, even in terms of the number of women who have heard about this service. The factors responsible, were living at a considerable distance from healthcare facility, and are comparatively from lower socio-economic status, uneducated, and Muslim. ${ }^{37}$ Notwithstanding, overall SDIP and Aama have contributed to improved MCH by catering to both demand and supply side barriers in respect to service uptake, and by responding to the requirements of population. ${ }^{26}$

"SUMATA Initiative" was launched in 2002 as a part of the Maternal and Neonatal Health (MNH) program implemented by the government. SUMATA in Nepali language means 'Care, Share and Prepare' to promote appropriate MNH behaviors and to improve utility and access of "safe motherhood services". SUMATA focused on social as well as medical dimensions of maternal mortality. Print materials, radio, street theatre, television dramas and birth preparedness package were used to convey the messages to women's family and community. ${ }^{48}$

The evaluation study was conducted in two districts and found that more than three-fourth of the people who participated in SUMATA reported that they used the information delivered through SUMATA initiative. There was an increase in knowledge of danger signs appearing during pregnancy, childbirth and postpartum period and the awareness on danger signs in newborns. An increased awareness about available schemes in the community (transportation and financing) targeting welfare of women and newborns was also recorded. There was significant difference in the other MNH indicators but could not be attributed to SUMATA initiative alone because of parallel initiatives in the same area. ${ }^{48}$

\section{Discussion}

The present review was conducted to collate the evidence on existing status of RMNCAH and BCC interventions in RMNCAH in SA countries, particularly Bangladesh, Nepal and India. In SA, India was the pioneer in launching the family planning programme in 1952, other 
SA countries followed later. ${ }^{36}$ Subsequently, the SA countries have achieved considerable development in health and socio-economic indicators. However, in general MCH outcomes remain poor and there is disparity of indicators within Nepal, India and Bangladesh e.g. south Indian states perform better against central and eastern states of India and plains in Nepal perform better than mountain and hilly regions. ${ }^{36}$ All three countries are trying to generate the resources to fulfil the demands nevertheless, they need further improvement.

The strong and mutual collaboration between the government, professional bodies, development agencies, NGOs and donors is present in the delivery of health services. As a result, substantial resources have been invested for improvement of RMNCAH. The improvement can be attributed to standard social, demographic and economic development of the countries, in addition to the particular initiatives. However, as literature suggests, there is need for further improvement as a very limited number of people are covered under publicly funded insurance schemes. ${ }^{49}$ There is unequal uptake of service utilisation in publicly funded health services.

SA faces many challenges in newborn health due to its cultural and socio-demographic diversity. Culture, religious belief, gender norms and perceptions of people play significant role in pregnancy and childbirth therefore, there is a need to consider these factors while framing the programme or policy to speed-up the improvement in health indicators. ${ }^{16}$ Furthermore, the three countries needs to intensify the strategies in poor performing regions in order to improve MMR. ${ }^{31}$ Within country there is a need to reduce the coverage gap between rural-urban, mountain-plains and different ethnic groups in order to improve the $\mathrm{MCH}$ indicators ${ }^{17,26}$

Greater autonomy among women significantly influences the utilisation of healthcare services such as ANC and childcare ${ }^{50}$; hence, women empowerment is a very important factor to improve $\mathrm{MCH}$ outcomes. The future of SA nations depends on its children, which constitute the majority of the population. For example in India every fifth individual is an adolescent between 10 and 19 years ${ }^{36}$ and in Nepal one individual out of three is under the age of $15 .{ }^{33}$ Therefore it is important to target these levels of the population to achieve health for all. $^{36}$

The BCC programmes have been successfully implemented in the SA region, however they need further improvements with regards to wider reach in most vulnerable and marginalised populations. The evidence for cost-effectiveness of the BCC interventions has been proven. In the past decade, donors have started to invest in BCC based on the positive findings from programme evaluation. The improvement in RMNCAH indicators can be attributed to multiple initiatives wherein the contribution of BCC is massive, because of its wide reach in the community and among all age-groups.

The number of studies undertaken in the region have also suggested beneficial effect of BCC. ${ }^{51}$ The evidence synthesis of systematic reviews by Nair and colleagues ${ }^{52}$ suggests that improving community participation and making local community aware about the healthcare rights have beneficial effect on maternal health outcomes. The review further states that BCC interventions delivered at home, use of mobile health technology, and nutrition targeted BCC along with food fortification are found to be effective. Therefore, a combination of culturally appropriate interventions along with BCC may achieve much better achievements. In spite of observing diversity within SA region, a number of contextual similarities are found, such as gender differences, which should be considered while designing the BCC interventions in these regions. ${ }^{52}$ Expanding the intervention and sustainability need availability of resources and funding which can be undertaken by government and NGOs. Involvement of community in decision making, bottom-up approach and strong political commitment are essential elements in intervention sustainability. ${ }^{53}$ Another important BCC tool i.e. use of mobile phones in SA has increased, e.g. in Nepal almost all households (93\%) own a mobile phone, about $29 \%$ own a radio and every second household have television. ${ }^{26,33}$ Owing to surge in access to wide communication channels may generate increase in BCC hence, we recommend to make use of these tools to deliver health messages.

The strength of the present study lies in the consolidated information on RMNCAH and data from reliable sources such as The World Bank, WHO and UNICEF. One of the major constraints in doing this review was the lack of or poor availability of recent, homogeneous data for the SA region. This raises the question of whether referring to SA as a coherent whole could be misleading considering the disparities, in terms of socio-economic status and the status of healthcare related to RMNCAH. As we could not find a report which evaluated or compared all the SA countries or at least Bangladesh, India and Nepal, it would be prudent to keep in mind intra-nation disparities are equally prevalent as inter-nation disparities. Lastly, as there was a lack of theoretical clarity about the procedure of BCC programs, the information education counselling initiatives can also be misinterpreted as BCC initiatives.

\section{Conclusion}

The South Asian countries have achieved considerable development in health indicators however the differences exist within and between countries. The BCC strategies have been proven to be a cost-effective measure, however, it should be designed considering the importance of context-specific methods. The BCC should be a continuous process so that the lasting impression on the health behaviour is achieved. BCC combined with other intervention can be important tool to successively achieving the health related targets.

\section{Conflicts of interest}

None declared.

\section{Acknowledgement}

We extend our thanks to Dr. Bhumika T.V., Assistant Professor, Public Health Evidence South Asia, Manipal Academy of Higher Education, Manipal, and Prof. N Sreekumaran Nair, Professor and Head, Dept. of Biostatistics (Biometrics), Jawaharlal Institute of Postgraduate Medical Education and Research, Puducherry, for providing all the support required for the review. Study did not include human participants directly, hence ethical clearance was not relevant. The authors did not receive any funding for conducting this study.

\section{Appendix A. Supplementary data}

Supplementary data to this article can be found online at https:// doi.org/10.1016/j.cegh.2019.08.014.

\section{References}

1. Every Newborn: An Action Plan to End Preventable Deaths. Geneva: World Health Organization; 2014. Available from: https://apps.who.int/iris/bitstream/handle/ 10665/127938/9789241507448_eng.pdf;jsessionid = 630EBE63D9385580CA5967C7023C5143? sequence $=1$.

2. Acting on the Call: Ending Preventable Child and Maternal Deaths: A Focus on Health System. USAID; 2017. Available from: https://www.usaid.gov/sites/default/files/ documents/1864/USAID 2017_AOTC_final.pdf.

3. Darmstadt GL, Tarigopula UK. Behaviour change communication as an intervention to improve family health outcomes. J Fam Welf. 2010;56.

4. de Graft-Johnson J, Kerber K, Tinker A, et al. The maternal, newborn and child health: continuum of care. In: Lawn J, Kerber K, editors. Opportunities for Africa's Newborns: Practical Data, Policy and Programmatic Support for Newborn Care in Africa. Partnership for Maternal, Newborn \& Child Health (PMNCH).

5. Sponsored symposium: strategic behaviour change approaches to optimize the impact of micronutrient interventions. Micronutrient Forum Global Conference. Addis Ababa, Ethiopia: World Health Organization; 2014. Available from: https://www. who.int/nutrition/events/2014_WHOMI_symposium_behaviour_change_ micronutrient intervention/en/.

6. Strategic Communication - for Behaviour and Social Change in South Asia. Kathmandu, Nepal: The United Nations Children's Fund (UNICEF), Regional Office for South Asia; 2005. Available from https://www.unicef.org/cbsc/files/Strategic_Communication_ for_Behaviour_and_Social_Change.pdf. 
7. Accelerating Progress towards Achieving Maternal and Child Health Millennium Development Goals (MDGs) 4 and 5 in South-East Asia. World Health Organization, Regional Office for South-East Asia; 2009. Available from: http://www.who.int/iris/ handle/10665/204740.

8. Sustainable Development Goals. Washington, D.C.: Global Giving; 2019. Available from: https://www.globalgiving.org/sdg/?rf = ggad 19\&gclid = EAIaIQobChMIo7 Nppjr4QIViIyPCh3-4QYJEAAYASAAEgLm0PD_BwE.

9. The State of the World's Children 2014 in Numbers: Every Child Counts. New York: United Nations Children's Fund (UNICEF); 2014. Available from: https://www. unicef.org/publications/index_71829.html.

10. World Health Statistics 2018: Monitoring the Health for the SDGs, Sustainable Development Goals. Geneva: World Health Organization; 2018. Available from https://apps.who.int/iris/bitstream/handle/10665/272596/9789241565585-eng. pdf.

11. Maternal and Child Health Priority Countries USAID. 2019; 2019. Available from https://www.usaid.gov/what-we-do/global-health/maternal-and-child-health/ priority-countries.

12. El-Saharty S, Ohno N, Sarker I, Secci F, Alam BB. Bangladesh - Maternal and Reproductive Health at a Glance (English). Health, Nutrition, and Population Global Practice Knowledge Brief. Washington, DC: World Bank Group; 2014. Available from: http://documents.worldbank.org/curated/en/773411468013851896/BangladeshMaternal-and-reproductive-health-at-a-glance.

13. Rajia S, Sabiruzzaman M, Islam M, Hossain M, Lestrel P. Trends and future of maternal and child health in Bangladesh. PLoS One. 2019;14(3):e0211875.

14. Yap JT. Addressing Inequality in Southeast Asia through Regional Economic Integration. . Available from: https://www.ide.go.jp/library/English/Publish/ Download/Brc/pdf/14_01.pdf.

15. Trends in Maternal Mortality: 1990 to 2015. Geneva, Switzerland: WHO, UNICEF, UNFPA, World Bank Group and the United Nations Population Division; 2015. Available from:https://apps.who.int/iris/bitstream/handle/10665/194254/ 9789241565141_eng.pdf? sequence $=1$.

16. Khan NN. Maternal and child health in Bangladesh: a critical look at the policy and the sustainable development goals. Asian J Med Biol Res. 2017;3(3):298-304.

17. Kumar C, Singh PK, Rai RK. Coverage gap in maternal and child health services in India: assessing trends and regional deprivation during 1992-2006. J Public Health. 2013;35(4):598-606.

18. . Available from: World Bank Country and Lending Groups. The World Bank; 2019. Available from https://datahelpdesk.worldbank.org/knowledgebase/articles/ 906519-world-bank-country-and-lending-groupshttps://datahelpdesk.worldbank. org/knowledgebase/articles/906519-world-bank-country-and-lending-groups.

19. Bhutta ZA, Gupta I, de'Silva H, et al. Maternal and child health: is South Asia ready for change? BMJ. 2004;328(7443):816-819.

20. Shakya K. Achievements of millennium development goals (MDGs) in South asian association of regional corporations (SAARC) countries: a case of Nepal. J Pro Poor Growth. 2013;1:19-28.

21. Annadurai K, Danasekaran R, Mani G. Elimination of maternal and neonatal tetanus in India: a triumph tale. Int J Prev Med. 2017;8:15.

22. Maternal Mortality Ratio (Per 100000 Live Births). World Health Organization; 2019. Available from https://www.who.int/healthinfo/statistics/indmaternalmortality/ en/.

23. Reproductive, Maternal, Newborn, Child, Adolescent Health and Undernutrition. Health in 2015: From MDGs to SDGs. Geneva, Switzerland: World Health Organization: Global Health Observatory; 2015. Available from: https://www.who. int/gho/publications/mdgs-sdgs/chapter4_snapshots/en/.

24. Success Factors for Women's and Children's Health: Country Specific Review of Data and Literature on 10 Fast-Track Countries' Progress towards MDGs 4 and 5. Options Consultancy Services/Evidence for Action (E4A), Cambridge Economic Policy Associates (CEPA), \& the Partnership for Maternal, Newborn \& Child Health (PMNCH). 2013; 2013. Available from: https://www.who.int/pmnch/knowledge/publications/ country_data_review.pdf?ua $=1$.

25. Kumar S, Kumar N, Vivekadhish S. Millennium development goals (MDGs) to sustainable development goals (SDGs): addressing unfinished agenda and strengthening sustainable development and partnership. Indian J Community Med. 2016;41(1):1-4.

26. Success Factors for Women's and Children's Health. Nepal: World Health Organization \& Ministry of Health and Population, Nepal; 2015. Available from: http://www.who. int/iris/handle/10665/254482.

27. Success Factors for Women's and Children's Health. Bangladesh: World Health Organization \& Bangladesh. Ministry of Health and Family Welfare; 2015. Available from: http://www.who.int/iris/handle/10665/178623.

28. Victora C, Requejo J, Boerma T, et al. Countdown to 2030 for reproductive, maternal, newborn, child, and adolescent health and nutrition. Lancet Glob Health 2016;4(11):e775-e776.

29. Mortality Rate, Infant (Per 1,000 Live Births). UNICEF, WHO, World Bank, UN DESA Population Division; 2019. Available from: https://data.worldbank.org/indicator/ sp.dyn.imrt.in?view $=$ chart.

30. Mortality Rate, Under-5 (Per 1,000 Live Births). UNICEF, WHO, World Bank, UN DESA Population Division; 2019. Available from: https://data.worldbank.org/indicator/ sh.dyn.mort.

31. Annual Report of Department of Health and Family Welfare 2017-18. New Delhi,
India: Department of Health \& Family Welfare, Ministry of Health \& Family Welfare, Government of India. Available from: https://mohfw.gov.in/basicpage/annualreport-department-health-and-family-welfare-2017-18.

32. INAP: India Newborn Action Plan. New Delhi, India: Child Health Division, Ministry of Health \& Family Welfare (MoHFW): Government of India; 2014. Available from: https://www.newbornwhocc.org/INAP_Final.pdf.

33. 2016 Nepal Demographic and Health Survey Key Findings. Kathmandu, Nepal: Ministry of Health, Nepal; New ERA; and ICF; 2017. Available from: https://nepal.unfpa.org/ sites/default/files/pub-pdf/NDHS\%202016\%20key\%20findings.pdf.

34. Strategic Approach to Reproductive, Maternal, Newborn, Child and Adolescent Health $(\mathrm{RMNCH}+\mathrm{A})$ in India. New Delhi, India: Ministry of Health and Family Welfare; 2013.

35. Bangladesh Reproductive Health Vouchers: Demand-Side Financing (DSF). Center for Health Market Innovations.

36. Born to Be: 25 Years of India's Progress in Maternal and Child Health. New Delhi, India: Ministry of Health and Family Welfare; 2015.

37. Upreti SR, Baral SC, Tiwari S, et al. Rapid Assessment of the Demand Side Financing Schemes: Aama Programme and 4ANC. Kathmandu, Nepal: Ministry of Health and Population; Nepal Health Sector Support Programme and Health Research and Social Development Forum. 2012; 2012.

38. National Policy on Skilled Birth Attendants, Supplementary to Safe Motherhood Policy 1998. 2006; 2006.

39. A Case Study on the Factors Which Influenced a HiAP Response to Nutrition. WHOSEARO; 2013. Available from: http://www.searo.who.int/entity/healthpromotion/ case-study-nepal.pdf?ua $=1$

40. Behavior Change Communication \& Community Mobilization: Within the Healthy Fertility Study. USAID, Bangladesh Ministry of Health and Family Welfare, Shimantik, the Center for Data Processing and Analysis, ACCESS-FP, and the Johns Hopkins Bloomberg School of Public Health. Available from: https://www.mchip. net/sites/default/files/HFS\%20BCC\%20CM\%20Brief\%20FINAL.pdf.

41. Kilkari: A Maternal and Child Health Service in India Lessons Learned and Best Practices for Deployment at Scale. London: GSMA, Bill and Melinda Gates Foundation, USAID; 2016. Available from: https://www.gsma.com/mobilefordevelopment/wp-content/ uploads/2016/10/mHealth-Kilkari-a-maternal-and-child-health-service-in-India.pdf.

42. Reaching the Every Newborn National 2020 Milestones: Country Progress, Plans and Moving Forward. Geneva, Switzerland: World Health Organization, UNICEF; 2017. Available from: https://www.who.int/maternal_child_adolescent/documents/everynewborn-progress-2017/en/.

43. Nepal's Every Newborn Action Plan. Kathmandu, Nepal: Government of Nepal, Ministry of Health; 2016. Available from: https://www.healthynewbornnetwork. org/hnn-content/uploads/NENAP-final-low-resolution.pdf.

44. Mehra D, Sarkar A, Sreenath P, Behera J, Mehra S. Effectiveness of a community based intervention to delay early marriage, early pregnancy and improve school retention among adolescents in India. BMC Public Health. 2018;18(1):732.

45. Chesterton P. Evaluation of the Meena Communication Initiative. Kathmandu, Nepal: United Nations Children's Fund (UNICEF) Regional Office for South Asia. 2004; 2004. Available from https://www.unicef.org/french/evaldatabase/files/ROSA_2004_800 Meena Comm Initiative.pdf.

46. Hoddinott J, Ahmed I, Ahmed A, Roy S. Behavior change communication activities improve infant and young child nutrition knowledge and practice of neighboring non-participants in a cluster-randomized trial in rural Bangladesh. PLoS One. 2017;12:e0179866.

47. Khan M, Darmstadt G, Tarigopula U, Ganju D, Donnay F, eds. Shaping Demand and Practices to Improve Family Health Outcomes- Designing a Behavior Change Communication Strategy in India, Volume I: Uttar Pradesh, Volume II. Bihar: SAGE Publishing; 2012.

48. Sood S, Chandra U, Mishra P, Neupane S. Measuring the Effects of Behavior Change Interventions in Nepal with Population-Based Survey Results. Baltimore: JHPIEGO; 2004. Available from: http://reprolineplus.org/system/files/resources/bci_nepal.pdf.

49. Singh P, Kumar V. Insurance coverage under different health schemes in Uttar Pradesh, India. Clin Epidemiol Glob Health. 2017;5(1):33-39.

50. Mahapatro SR. Utilization of maternal and child health care services in India: does Women's Autonomy matters? J Fam Welf. 2012;58(1):22-33.

51. Mahanta TG, Boruah M, Singh VK, Gogoi P, Rane T, Mahanta BN. Effect of social and behavior change communication by using infotainment in community perception of adolescent girls for reproductive and sexual health care in high priority districts of Assam. Clin Epidemiol Glob Health. 2016;4(3):133-139.

52. Nair N, Darak S, Parsekar S, et al. Effectiveness of Behaviour Change Communication interventions in improving the delivery of health messages for ante-natal care in limited literacy settings: An evidence summary. London: EPPI-Centre, Social Science Research Unit, UCL Institute of Education, University College London; 2017. Available from: https://eppi.ioe.ac.uk/cms/Portals/0/PDF\%20reviews\%20and\%20summaries/ BCC\%202017\%20report 291117.pdf?ver $=$ 2018-04-27-152513-020.

53. Lassi Z, Kumar R, Bhutta Z. Community-based care to improve maternal, newborn, and child health. 3 ed.In: Black RE ea, ed. Reproductive, Maternal, Newborn, and Child Health: Disease Control Priorities. vol 2. Washington (DC): The International Bank for Reconstruction and Development and The World Bank; 2016. Available from https:// www.ncbi.nlm.nih.gov/books/NBK361898/. 